\title{
JURNAL \\ ANALISIS KINERJA KEUANGAN SEBELUM DAN SESUDAH PENERAPAN PPK-BLUD PADA RSUD KARDINAH
}

\author{
Debby Firoeza Indiany, Dien Noviany Rahmatika dan Jaka Waskito \\ BPRS HIK, Universitas Pancasakti Tegal, dan Universitas Pancasakti Tegal \\ Melati.putih1501@gmail.com
}

\begin{abstract}
RSUD Kardinah Kota Tegal in December, 2008 has been designated as Badan Layanan Umum Daerah (BLUD), then since January 2009 has done changes management finances, with the financial management apply system that is called "Pola Pengelolaan Keuangan Badan Layanan Umum Daerah" (PPK - BLUD). This study aimed to analyze the diffrerences in financial performance RSUD Kardinah based on (1) the ratio of the vulnerability, the aspects of return of assets, return on equity, gross profit margin and net profit margin. (2) liquidity ratios include aspects of current ratio, quick ratio and cash ratio (3) solvency ratios include aspects of debt ratios, debt to equity ratio and times interest earned ratio, and (4) the ratio of activity includes aspects of accounts receivable turn over, inventory turn over, fixed assets and total assets turn over before and after implementing PPK-BLUD. This study classified quantative descriptive research the type of data used is secondary data obtained from the annual financial statements of RSUD Kardinah, the period before implementing ppk - blud (2002 - 2008) and after implementing ppk - blud (2009-2015). The analytical method used is a diferrent test to test the hypothesis using wilcoxon test with an error rate (alpha) of 5\%. The result of this study conclude, there are no significant differences in financial performance based suspectible ratio, liquidity ratio and activity ratio on RSUD Kardinah before and after implementing of PPK-BLUD. There are significant differences in the aspect ratio of the activity inventory turn over snd fixed assets turn over before and after implementing of PPK - BLUD. The implementation of the PPK$B L U D$ in hospitals Kardinah not give any significant changes to be seen from the ratio financial ratio, but there is an increase in the trend sharp against the income operations hospital after the implementation of $P P K-B L U D$.
\end{abstract}

Keywords : $P P K-B L U$, financial ratio analysis, financial performance, Wilcoxon Siged Ranks Test

\section{Latar Belakang}

Rumah sakit sebagai lembaga "nirlaba/non profit", sering dihadapkan pada suatu dilema yaitu di satu pihak harus menghadapi biaya-biaya yang terus meningkat dan tak terkendali akibat perkembangan ilmu pengetahuan dan teknologi serta inflasi, dan di lain pihak menghadapi ketidakmampuan masyarakat membayar jasa pelayanan kesehatan yang semakin mahal. Dilema tersebut dapat mengakibatkan situasi sebagai berikut :

1. Bila rumah sakit melaksanakan fungsi sosialnya dan tetap terus dikembangkan sesuai dengan perkembangan ilmu pengetahuan dan 
teknologi, maka rumah sakit akan dihadapkan pada masalah kesulitan arus kas (cash flow) yang akan mengakibatkan kesulitan keuangan (financial distress). Pada akhirnya akan berujung pada kebangkrutan.

2. Bila rumah sakit tetap terus melaksanakan fungsi sosialnya dan membatasi diri dalam mengikuti perkembangan ilmu pengetahuan dan teknologi, maka lambat laun mutu pelayanan kesehatan rumah sakit akan menurun.

3. Bila rumah sakit mengabaikan fungsi sosial dan hanya melayani masyarakat yang dapat membayar saja sehingga berubah menjadi for profit hospital, maka akan berubah menjadi institusi komersial.

Berdasarkan alasan tersebut maka rumah sakit harus melakukan perubahan manajemen rumah sakit, termasuk pengelolaan keuangan yang dapat meningkatkan kinerja rumah sakit, sehingga kinerja keuangan rumah sakit dalam kondisi sehat, mampu bersaing dan dapat memberikan pelayanan kesehatan yang bermutu sesuai kebutuhan masyarakat.

Perkembangan ekonomi dan dunia usaha telah menimbulkan persaingan yang makin tajam, demikian halnya dengan industri pelayanan kesehatan sebagai dampak kemajuan teknologi bidang kesehatan menuntut pembiayaan dan investasi yang sangat mahal, sementara itu kemampuan pemerintah dalam membiayai pelayanan kesehatan masyarakat semakin terbatas. Oleh karena itu perlu memberikan otonomi rumah sakit pemerintah, dengan memberikan ruang gerak yang lebih leluasa bagi rumah sakit untuk mengoptimalkan pemanfaatan sumber dayanya, agar lebih efektif dan efisien sejalan dengan praktek bisnis yang sehat tanpa mengutamakan pencarian keuntungan.
Dalam rangka upaya tersebut perlu dilakukan penataan kembali manajemen rumah sakit, termasuk pola pengelolaan keuangannya, agar rumah sakit dapat beroperasi denga lebih efektif dan efisien dalam penyelenggaraan pelayanan kesehatan kepada masyarakat, maka rumah sakit perlu diberikan status sebagai Badan Layanan Umum (BLU). Diharapkan dengan status tersebut kondisi keuangan rumah sakit lebih sehat dan pelayanan kepada masyarakat menjadi lebih baik dan mutu pelayanan kesehatan meningkat.

Jahra N (2013), dalam penelitiannya yang berjudul Analisis Implementasi Pola Pengelolaan Badan Layanan Umum Pada Rumah Sakit Daerah Kalisat Jember, tujuan penelitian ini untuk menunjukkan pengaruh implementasi PPK-BLUD di RSUD Kaliasat Jember. Berdasarkan analisis didapatkan bahwa PPK-BLUD berpengaruh secara signifikan terhadap kinerja keuangan, kinerja pelayanan serta kinerja mutu dan manfaat bagi masyarakat sesudah penerapan PPK-BLUD.

Maharani A, Adi W, Muhtar (2013), dengan judul penelitian Analisis Kinerja Keuangan Sebelum Dan Sesudah Penerapan Pola Pengelolaan Keuangan Badan Layanan Umum (PPKBLU) di Universitas Sebelas Maret, dengan teknis analisis data menggunakan Paired Sample t-test, menunjukkan bahwa tidak terdapat perbedaan kinerja keuangan yang signifikan antara sebelum dan sesudah penerapan PPKBLU, tetapi kinerja keuangan setelah penerapan PPK-BLU cenderung meningkat dan lebih baik.

Surya SK (2015) dalam penelitian yang berjudul Analisis kinerja Keuangan dan Non Keuangan Rumah Sakit Umum Daerah Dr, Haryoto Lumajang Sebelum dan Sesudah Implementasi Badan Layanan Umum, hasilnya aspek likuiditas dan solvabilitas menga- 
lami kenaikan, sedangkan rentabilitas, cost recovery rate dan tingkat kemandirian mengalami penurunan sesudah berstatus BLUD.

Rumah Sakit Umum Daerah (RSUD) Kardinah Kota Tegal sejak tahun 2008 menjadi Badan Layanan Umum Daerah (BLUD) sesuai dengan Keputusan Walikota Tegal No. 445/244/ 2008 tentang Penetapan Rumah Sakit Umum Daerah ( RSUD ) Kardinah Kota Tegal sebagai unit kerja yang menerapkan Pola Pengelolaan Keuangan Badan Layanan Umum Daerah Secara Penuh, diberikan fleksibilitas berupa keleluasaan bagi pengelola untuk menerapkan prakti-praktik bisnis yang sehat guna meningkatkan pelayanan publik.

Dari uraian masalah tersebut, peneliti merasa perlu mengadakan penelitian yang bertujuan untuk mengetahui perbedaan kinerja keuangan RSUD Kardinah sebelum dan sesudah ditetapkan sebagai BLUD dengan Pola Pengelolaan Keuangan Badan Layanan Umum Daerah ( PPK-BLUD ).

\section{Tinjauan Pustaka}

Badan Layanan Umum (BLU) rumah sakit merupakan unit pelaksana teknis Kementerian Kesehatan yang diberi tugas dan wewenang untuk menyelenggarakan kegiatan jasa pelayanan, pendidikan, penelitian, dan pengembangan serta usaha lain dalam bidang kesehatan yang bertujuan untuk meningkatkan derajat kesehatan dan senantiasa berorientasi kepada kepentingan masyarakat.

Berdasarkan KEPMENKEU No.1981 TH 2010, BLU rumah sakit memiliki karakteristik, bahwa BLU rumah sakit bertujuan untuk meningkatkan pelayanan kesehatan kepada masyarakat dalam rangka memajukan kesejahteraan umum dan mencerdaskan kehidupan bangsa dengan memberikan fleksibilitas dalam pengelolaan keuangan berdasarkan prinsip efisiensi dan produktivitas, dan penerapan praktik bisnis yang etis dan sehat, serta tidak semata-mata mencari keuntungan.

Badan Layanan Umum Daerah yang selanjutnya disingkat BLUD adalah Satuan Kerja Perangkat Daerah atau Unit Kerja pada Satuan Kerja Perangkat Daerah di lingkungan pemerintah daerah yang dibentuk untuk memberikan pelayanan kepada masyarakat berupa penyediaan barang dan/atau jasa yang dijual tanpa mengutamakan mencari keuntungan, dan dalam melakukan kegiatannya didasarkan pada prinsip efisiensi dan produktivitas (Permendagri No.61, 2007: 4).

Dalam mengelola keuangannya disebut dengan Pola Pengelolaan Keuangan Badan Layanan Umum Daerah (PPK-BLUD), yaitu pengelolaan keuangan yang memberikan fleksibilitas berupa keleluasaan menerapkan praktikpraktik bisnis yang sehat untuk meningkatkan pelayanan kepada masyarakat dalam rangka memajukan kesejahteraan umum dan mencerdaskan kehidupan bangsa, sebagai pengecualian dari ketentuan pengelolaan keuangan Negara pada umumnya (Permendagri No.61, 2007: 1; Restianto YE, Bawono IR, 2015: 5 ).

\section{Kinerja Keuangan}

Kinerja merupakan suatau istilah secara umum yang digunakan untuk sebagian atau seluruhnya tindakan atau aktivitas dari suatau organisasi pada suatu periode dengan referensi pada sejumlah standar seperti biaya-biaya masa lalu atau yang diproyeksikan, dengan dasar efisiensi, pertanggungjawaban atau akuntabilitas manajemen dan semacamnya. 
Kinerja Keuangan merupakan gambaran kondisi keuangan perusahaan pada suatu periode tertentu menyangkut aspek penghimpunan dana maupun penyaluran dana, yang biasanya diukur dengan indikator kecukupan modal, likuiditas, dan profitabilitas.

Kinerja rumah sakit merupakan gambaran mengenai tingkat pencapaian pelaksanaan suatu kegiatan/program/ kebijaksanaan rumah sakit dalam mewujudkan sasaran, tujuan, misi, dan visi organisasi yang tertuang dalam perumusaan skema strategis (strategic planning) rumah sakit.

Pengukuran kinerja keuangan merupakan suatu usaha formal untuk mengevaluasi efisiensi dan efektivitas perusahaan dalam menghasilkan laba dan posisi kas tertentu.Dengan pengukuran kinerja keuangan ini dapat dilihat prospek pertumbuhan dan perkembangan perusahaan dari pemanfaatan sumber daya yang dimilikinya. Perusahaan dikatakan berhasil apabila perusahaan telah mencapai suatu kinerja tertentu yang telah ditetapkan.

Sesuai dengan Kep.Menkes.RI. No. 1164/Menkes/SK/X/2007 tentang Pedoman Penyusunan Rencana Bisnis dan Anggaran Rumah Sakit Badan Layanan Umum (BLU), dalam kaitannya

\section{Sebelum Penerapan PPK-BLUD}

dengan kinerja operasional rumah sakit, indikator kinerja yang digunakan dengan pendekatan 3 (tiga) aspek penilaian, yaitu aspek kinerja keuangan, aspek kinerja pelayanan dan aspek kinerja mutu pelayanan dan manfaat bagi masyarakat.

Evaluasi dan penilaian Kinerja rumah sakit dilihat dari aspek keuangan sebagaimana dimaksud pada pasal 127 ayat (1) Peraturan Menteri Dalam Negeri nomor 61 tahun 2007, dapat diukur berdasarkan tingkat kemampuan BLUD dalam:

1. Memperoleh hasil usaha atau hasil kerja dari layanan yang diberikan (rentabilitas)

2. Memenuhi kewajiban jangka pendeknya (likuiditas)

3. Memenuhi seluruh kewajibannya (solvabilitas)

4. Kemampuan penerimaan dari jasa layanan untuk membiayai pengeluaran

Dalam penelitian ini, kinerja keuangan rumah sakit diukur dengan menggunakan rasio-rasio keuangan meliputi rasio rentabilitas, rasio likuiditas, rasio solvabilitas dan rasio aktivitas, sebelum dan sesudah penerapan PPK-BLUD.

Sesudah Penerapan PPK-BLUD

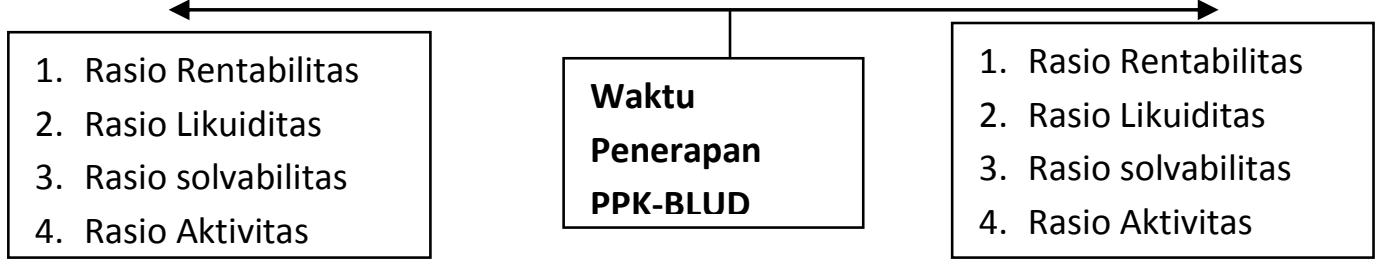

Gambar 1. Kerangka Pemikiran

Berdasarkan kerangka pemikiran, maka Hipotesis yang diajukan adalah sebagai berikut :
H1 : Terdapat perbedaan kemampuan memperoleh hasil usaha atau hasil kerja dari layanan yang diberikan rumah sakit (renta- 
bilitas) sebelum dan sesudah menerapkan PPK-BLUD

$\mathrm{H} 2$ : Terdapat perbedaan kemampuan rumah sakit untuk memenuhi kewajiban jangka pendeknya (liquiditas), sebelum dan sesudah menerapkan PPKBLUD.

H3 : Terdapat perbedaan kemampuan rumah sakit untuk memenuhi seluruh kewajibannya (solvabilitas), sebelum dan sesudah menerapkan PPK-BLUD.

H4 : Terdapat perbedaan tingkat efisiensi pembiayaan untuk operasional rumah sakit sebelum dan sesudah menerapkan PPK-BLUD.

\section{Metode Penelitian}

\section{Jenis Penelitian}

Penelitian ini merupakan penelitian retrospektif dengan menggunakan metode penelitian deskriptif dan komparatif. Penelitian retrospektif adalah penelitian yang berusaha melihat ke belakang, dimana penelitian menjelaskan data yang lalu. Metode deskriptif adalah penelitian yang dilakukan untuk mengetahui nilai variable mandiri, baik satu variable atau lebih (independen) tanpa membuat perbandingan, atau menghubungkan dengan variable lain. Sedang- kan metode komparatif adalah suatu penelitian yang bersifat membandingkan keberadaan suatu variable pada dua sampel atau lebih.

\section{Tempat dan Waktu Penelitian}

Penelitian ini dilakukan di RSUD Kardinah Kota Tegal, Provinsi Jawa Tengah.Waktu penelitian dilakukan pada bulan Juli sampai dengan Agustus 2016.

\section{Metode Pengumpulan Data}

Sampel dalam penelitian ini adalah laporan tahunan keuangan rumah sakit RSUD Kardinah tahun 2002 2019. Data yang digunakan pada penelitian ini adalah data Sekunder, yaitu diperoleh melalui catatan laporan keuangan RSUD Kardinah yang telah ada.

\section{Definisi Konsep dan Operasional Variabel}

Dalam penelitian tini variabel yang digunakan dalam penelitian ini bersifat independen yang artinya bebas atau tidak terikat oleh variabel lainnya. Variabel tersebut adalah rasio-rasio keuangan RSUD Kardinah yang terdiri dari rasio rentabilitas, rasio likuiditas, rasio solvabilitas dan rasio aktivitas.

Variabel dan Indikator Kinerja Keuangan

\begin{tabular}{|c|c|c|}
\hline Variabel & Definisi Konseptual & Indikator \\
\hline Ratio rentabilitas & $\begin{array}{l}\text { Seberapa besar kemampuan aset } \\
\text { perusahaan untuk menghasilkan } \\
\text { pendapatan }\end{array}$ & \begin{tabular}{|ll} 
1. & Return on Assets \\
2. & Return on Equity \\
3. & Gross Profit Margin \\
4. & Net Profit Margin \\
\end{tabular} \\
\hline Rasio likuiditas, & $\begin{array}{lrr}\text { Kemampuan } & \text { perusahaan } & \text { untuk } \\
\text { memenuhi } & \text { kewajiban } & \text { jangka } \\
\text { pendeknya yang segera } & \text { jatuh } \\
\text { tempo } & & \end{array}$ & $\begin{array}{l}\text { 1. } \text { Current Ratio } \\
\text { 2. Quick Ratio } \\
\text { 3. CashRatio }\end{array}$ \\
\hline Rasio solvabilitas, & $\begin{array}{l}\text { Kemampuan perusahaan dalam } \\
\text { memenuhi seluruh kewajibannya, }\end{array}$ & $\begin{array}{l}\text { 1. Debt Ratio } \\
\text { 2. Debt to Equity Ratio }\end{array}$ \\
\hline
\end{tabular}




\begin{tabular}{|l|l|l|}
\hline \multicolumn{1}{|c|}{ Variabel } & \multicolumn{1}{|c|}{ Definisi Konseptual } & \multicolumn{1}{c|}{ Indikator } \\
\hline & $\begin{array}{l}\text { baik jangka waktu pendek atau } \\
\text { janngka waktu panjang }\end{array}$ & $\begin{array}{l}\text { Times Interest } \\
\text { Earned Ratio }\end{array}$ \\
\hline Rasio aktivitas & $\begin{array}{l}\text { Mengukur tingkat efisiensi } \\
\text { (efektivitas ) pemanfaatan sumber } \\
\text { daya perusahaan }\end{array}$ & $\begin{array}{l}\text { 1. AccountsReceivable } \\
\text { Turn Over } \\
\text { Inventory Turn Over } \\
\text { Fixed Asset Turn } \\
\text { Over } \\
\text { Total Assets Turn } \\
\text { Over }\end{array}$ \\
\hline
\end{tabular}

Sumber : Permenkes No : 1164/MENKES/SK/X/2007

\section{a. Rasio Rentabilitas}

Rasio Rentabilitas disebut juga Rasio Profitabilitas, merupakan rasio yang menggambarkan kemampuan perusahaan dalam menghasilkan laba. Rasio ini dapat dibedakan menjadi dua jenis, yaitu Rasio Tingkat Pengembalian atas Investasi dan Rasio Kinerja Operasi

1. Tingkat Pengembalian atas Investasi, terdiri dari Hasil Pengembalian atas Aset (Return on Assets) dan Hasil Pengembalian atas Ekuitas (Return on Equity)

$$
\text { Return on Assets }=\frac{\text { Laba Bersih }}{\text { Total Aset }}
$$

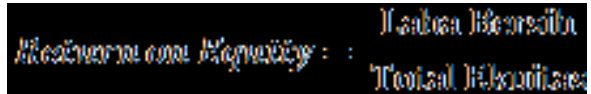

2. Rasio Kinerja Operasi, terdiri dari Margin Laba Kotor (Gross Profit Margin), Margin Laba Operasional (Operating Profit Margin) dan Margin Laba Bersih (Net Profit Margin)

$$
\begin{aligned}
\text { Gross Profit Margin } & =\frac{\text { Laba Kotor }}{\text { Penjualan Bersih }} \\
\text { Net Profit Margin } & =\frac{\text { Laba Bersih }}{\text { Penjualan Bersih }}
\end{aligned}
$$

\section{b. Rasio likuiditas}

Merupakan ratio yang menggambarkan kemampuan perusahaan untuk memenuhi kewajiban jangka pendeknya yang segera jatuh tempo. Rasio ini likuiditas diperlukan untuk kepentingan analis kredit atau analis risiko keuangan.

Ratio likuiditas terdiri atas Rasio Lancar (Current Ratio), dan Rasio Sangat Lancar atau Rasio Cepat (Quick Ratio atau Acid Test Ratio).

\section{Rasio Lancar (Current Ratio)}

Merupakan rasio untuk mengukur kemampuan perusahaan dalam memenuhi kewajiban jangka pendeknya yang segera jatuh tempo dengan menggunakan aset lancar yang tersedia.

$$
\text { Current Ratio }=\frac{\text { Aktiva Lancar }}{\text { Hutang Lancar }}
$$

2. Rasio Sangat Lancar atau Rasio Cepat (Quick Ratio)

Merupakan Ratio untuk mengukur kemampuan perusahaan memenuhi kewajiban 
finansialnya atas aktiva paling liquid.

Rumus :

QuickRatio $=\frac{\text { Aktiva Lancar }- \text { Persediaan }}{\text { Hutang Lancar }} \times 100 \%$

3. Rasio Kas (Cash Ratio).

Merupakan rasio yang digunakan untuk mengukur kemampuan perusahaan memenuhi kewajiban financial kas dan bank.

CashRatio $=\frac{\text { Kas (Bank) }}{\text { Kewajiban Lancar }} \times 100 \%$

\section{c. Rasio Solvabilitas (Leverage} Ratio)

Merupakan Rasio yang menggambarkan kemampuan perusahaan dalam memenuhi seluruh kewajibannya, baik jangka waktu pendek atau janngka waktu panjang.

\section{Rasio Utang (Debt Ratio),} Merupakan Rasio yang digunakan untuk mengukur perbandingan antara total utang dengan total aset.

Debt Ratio $=\frac{\text { Total Hutang }}{\text { Total Aktiva }}$

\section{Ratio Utang terhadap} Ekuitas (Debt to Equity Ratio) Merupakan rasio yang digunakan mengukur perbandingan antara total utang dengan total ekuitas.

Debt to Equity Ratio $=\frac{\text { Total Hutang }}{\text { Total Modal }}$

3. Rasio Kelipatan Bunga yang Dihasilkan (Times Interest Earned Ratio)

Merupakan rasio yang menunjukkan kemampuan perusahaan dalam membayar bunga. Kemampuan perusahaan disini diukur dari jumlah laba sebelum bunga dan pajak

Time Interest Earned Ratio $=\frac{\text { Laba sebelum Bunga dan Pajak }}{\text { Beban Bunga }}$

d. Rasio Aktivitas

Merupakan rasio yang digunakan untuk mengukur tingkat efisiensi atas pemenfaatan sumber daya yang dimiliki perusahaan, atau untuk menilai kemampuan perusahaan dalam menjalankan aktivitasnya sehari-hari.Rasio ini dikenal juga sebagai rasio pemanfaatan aset.

1. Perputaran Piutang Usaha (Recible Turn Over )

Merupakan rasio yang digunakan untuk mengukur berapa lama penagihan piutang usaha atau berapa kali dana yang tertanam dalam piutang usaha akan berputar dalam satu periode.

Recible Tum Over $=\frac{\text { PenjualanKedit }}{\text { Rata-lataPiutangUaha }}$

\section{Perputaran Persediaan} (Inventory Turn Over)

Merupakan rasio yang digunakan untuk mengukur berapa kali dana yang tertanam dalam persediaan akan berputar dalam satu periode.

InventoryTurn0ver $=\frac{\text { Ponjualan }}{\text { Rata-rataPersediaan }}$

3. Perputaran Aset Tetap (Fixed Assets Turn Over)

Merupakan rasio yang digunakan untuk mengukur keefektifan aset tetap yang 
dimiliki perusahaan dalam menghasilkan penjualan.

\section{Fixed Asset Turm Over $=\frac{\text { Penjualan }}{\text { Rata-rataAset Tetap }}$}

4. Perputaran Total Aset (Total Assets Turn Over)

Merupakan rasio yang digunakan untuk mengukur berapa jumlah penjualan yang akan dihasilkan dari setiap rupiah dana yang tertanam dalam total aset.

Total Assets Turn Over $=\frac{\text { Penjualan }}{\text { Rata }- \text { rata Total Aset }}$

\section{Uji Beda Sampel Berpasangan}

Untuk uji beda sampel berpasangan pada penelitian ini menggunakan Uji Wilcoxon yaitu pengujian noparametrik yang digunakan untuk membandingkan dua kelompok yang berpasangan dengan data kuantitatif yang tidak berdistribusi normal. Dalam penelitian ini untuk menguji perbedaan kinerja keuangan sebelum dan sesudah penerapan PPK-BLUD melalui penghitungan rasio-rasio keuangan.

\section{Hasil dan Pembahasan}

Tabel berikut ini menunjukkan mengenai kinerja keuangan RSUD Kardinah dilihat sebelum dan sesudap penerapan PPK-BLUD.

Tabel 2. Hasil Penghitungan Statistik Deskriptif terhadap Variabel-Variabel Penelitian Sebelum PPK-BLUD

\begin{tabular}{|c|l|c|c|c|c|}
\hline \multirow{2}{*}{ NO } & \multirow{2}{*}{ RASIO } & \multicolumn{3}{c|}{ SEBELUM PPK-BLUD } \\
\cline { 3 - 6 } & & MIN & MAX & MEAN & SD \\
\hline $\mathbf{1}$ & Rasio Rentabilitas & & & & \\
\hline & Return on Assets (\%) & 96,07 & $2.228,79$ & 666,11 & 980,03 \\
\hline & Net Return on Equity (\%) & 0,38 & 8,74 & 4,51 & 2,99 \\
\hline & Gross Profit Margin (\%) & 1,94 & 16,09 & 10,38 & 5,50 \\
\hline & Net Profit Margin (\%) & 1,97 & 19,31 & 11,62 & 6,47 \\
\hline $\mathbf{2}$ & Rasio Likuiditas & & & & \\
\hline & Current Ratio (\%) & 152,92 & $1.155,80$ & 418,29 & 345,64 \\
\hline & Quick Ratio (\%) & 0,59 & 8,54 & 2,84 & 2,68 \\
\hline & Cash Ratio (\%) & 9,69 & 369,58 & 150,11 & 128,26 \\
\hline $\mathbf{3}$ & Rasio Solvabilitas / Leverage & & & & \\
\hline & Debt Total Asset (\%) & 1,31 & 65,39 & 18,27 & 26,30 \\
\hline & Debt to Equity Ratio (\%) & 1,54 & 4,41 & 3,16 & 0,99 \\
\hline \multirow{2}{*}{$\mathbf{4}$} & Times Interest Earned Ratio & 48,56 & 416,95 & 261,60 & 107,82 \\
\hline & Rasio Aktivitas & & & & \\
\hline & Account Receible Turn Over & 7,53 & 78,24 & 22,77 & 24,86 \\
\hline & Inventory Turn Over & 7,11 & 14,56 & 10,67 & 2,33 \\
\hline & Fixed Asset Turn Over & 0,20 & 0,64 & 0,41 & 0,16 \\
\hline & Total Assets Turn Over & 2,91 & 4,51 & 3,67 & 0,67 \\
\hline
\end{tabular}

Sumber : data olahan 
Tabel 3. Hasil Penghitungan Statistik Deskriptif terhadap Variabel-Variabel Penelitian Sesudah PPK-BLUD

\begin{tabular}{|c|l|c|c|c|c|}
\hline \multirow{2}{*}{ NO } & \multicolumn{1}{|c|}{ RASIO } & \multicolumn{3}{c|}{ SESUDAH PPK-BLUD } \\
\cline { 3 - 6 } & & MIN & MAX & MEAN & SD \\
\hline $\mathbf{1}$ & Rasio Rentabilitas & & & & \\
\hline & Return on Assets (\%) & 41,44 & 100,00 & 88,61 & 21,22 \\
\hline & Net Return on Equity (\%) & 3,37 & 47,58 & 12,00 & 16,01 \\
\hline & Gross Profit Margin (\%) & 0,43 & 11,33 & 6,09 & 3,72 \\
\hline & Net Profit Margin (\%) & 0,46 & 12,59 & 6,85 & 4,24 \\
\hline $\mathbf{2}$ & Rasio Likuiditas & & & & \\
\hline & Current Ratio (\%) & 121,34 & 720,46 & 391,53 & 221,31 \\
\hline & Quick Ratio (\%) & 0,90 & 334,15 & 71,98 & 129,27 \\
\hline & Cash Ratio (\%) & 32,59 & 319,72 & 172,93 & 119,88 \\
\hline $\mathbf{3}$ & Rasio Solvabilitas / Leverage & & & & \\
\hline & Debt Total Asset (\%) & 1,13 & 12,91 & 5,61 & 4,76 \\
\hline & Debt to Equity Ratio (\%) & 1,53 & 100,00 & 3,16 & 0,99 \\
\hline & Times Interest Earned Ratio & 145,16 & $3.532,01$ & 552,63 & 186,57 \\
\hline $\mathbf{4}$ & Rasio Aktivitas & & & & \\
\hline & Account Receible Turn Over & 6,84 & 519,47 & 149,41 & 194,19 \\
\hline & Inventory Turn Over & 11,40 & 36,34 & 22,91 & 10,16 \\
\hline & Fixed Asset Turn Over & 0,56 & 1,46 & 0,83 & 0,29 \\
\hline & Total Assets Turn Over & 2,11 & 7,07 & 4,48 & 1,84 \\
\hline
\end{tabular}

Sumber : data olahan

Untuk membuktikan adanya perbedaan kinerja keuangan sebelum dan sesudah penerapan PPK-BLUD pada RSUD Kardinah, dilakukan uji Hipotesa H1, H2,
H3 dan $\mathrm{H} 4$ dengan menggunakan Uji beda berpasangan masing-masing variable dengan Wilcoxon Signed Ranks Test

\section{REKAPITULASI HASIL UJI HIPOTESA}

\begin{tabular}{|c|c|c|c|c|}
\hline No & VARIABEL & $\begin{array}{c}\text { TREN SBL } \\
\text { DAN SDH } \\
\text { PPK-BLUD }\end{array}$ & $\begin{array}{c}\text { UJI BEDA } \\
\text { WILCOXON }\end{array}$ & PENYEBAB \\
\hline 1 & $\begin{array}{l}\text { RASIO } \\
\text { RENTABILIT } \\
\text { AS } \\
\text { a. Gross Profit } \\
\quad \text { Margin } \\
\\
\text { b. Net Profit } \\
\text { Margin }\end{array}$ & 更 & 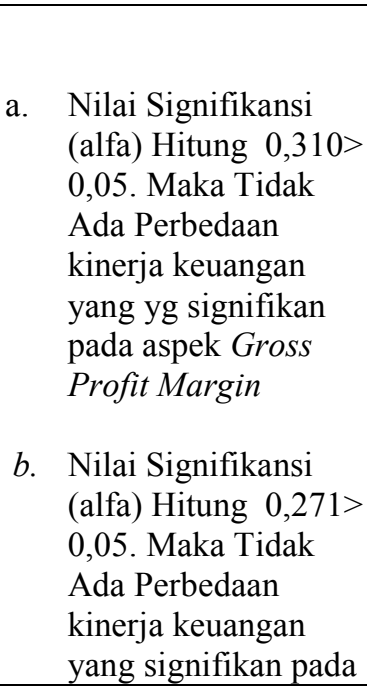 & 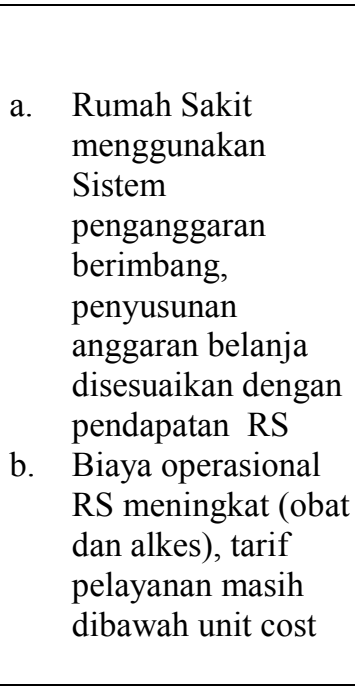 \\
\hline
\end{tabular}




\begin{tabular}{|c|c|c|c|c|}
\hline No & VARIABEL & $\begin{array}{l}\text { TREN SBL } \\
\text { DAN SDH } \\
\text { PPK-BLUD }\end{array}$ & $\begin{array}{c}\text { UJI BEDA } \\
\text { WILCOXON }\end{array}$ & PENYEBAB \\
\hline & $\begin{array}{ll}\text { c. } & \begin{array}{l}\text { Return on } \\
\text { Assets }\end{array} \\
& \\
\text { d. Net Return } \\
\text { on Equity }\end{array}$ & 更 & $\begin{array}{ll} & \text { aspek Net Profit } \\
& \text { Margin } \\
\text { c. } & \text { Nilai Signifikansi } \\
\text { (alfa) Hitung 0,499> } & \text { 0,05. Maka Tidak } \\
\text { Ada Perbedaan } \\
\text { kinerja keuangan } \\
\text { yang yg signifikan } \\
\text { pada aspek Net } \\
\text { Return on Assets } \\
\text { d. } & \text { Nilai Signifikansi } \\
\text { (alfa) Hitung 0,499> } \\
\text { 0,05. Maka Tidak } \\
\text { Ada Perbedaan } \\
\text { kinerja keuangan } \\
\text { yang yg signifikan } \\
\text { pada aspek Net } \\
\text { Return on Equity }\end{array}$ & $\begin{array}{ll}\text { c. } & \text { Tidak semua assets } \\
\text { RS menghasilkan } \\
\text { pendapatan dan } \\
\text { pemanfaatan asset } \\
\text { hanya yang sesuai } \\
\text { indikasi medis } \\
\\
\text { d. } & \begin{array}{l}\text { Sistem } \\
\text { penganggaran } \\
\text { berimbang }\end{array}\end{array}$ \\
\hline \multirow[t]{2}{*}{2} & $\begin{array}{l}\text { RASIO } \\
\text { LIKUIDITAS } \\
\text { a. } \quad \text { Cash Ratio }\end{array}$ & Naik & $\begin{array}{l}\text { a. Nilai Signifikansi } \\
\text { (alfa) Hitung 0,612> } \\
0,05 . \text { Maka Tidak } \\
\text { Ada Perbedaan } \\
\text { kinerja keuangan } \\
\text { yang yg signifikan } \\
\text { pada aspek Cash } \\
\text { Ratio }\end{array}$ & $\begin{array}{l}\text { a. Pendapatanan } \\
\text { operasional RS dapat } \\
\text { digunakan langsung } \\
\text { untuk pembiayaan ( } \\
\text { Cash flow lancar ) }\end{array}$ \\
\hline & $\begin{array}{l}\text { b. Quick Ratio } \\
\\
\text { c. Current } \\
\text { Ratio }\end{array}$ & 更 & $\begin{array}{ll}\text { b. } & \text { Nilai Signifikansi } \\
\text { (alfa) Hitung 0,237> } \\
\text { 0,05. Maka Tidak } \\
\text { Ada Perbedaan } \\
\text { kinerja keuangan } \\
\text { yang yg signifikan } \\
\text { pada aspek Quick } \\
\text { Ratio } \\
\text { c. Nilai Signifikansi } \\
\text { (alfa) Hitung 0,237> } \\
\text { 0,05. Maka Tidak } \\
\text { Ada Perbedaan } \\
\text { kinerja keuangan } \\
\text { yang yg signifikan } \\
\text { pada aspek Current } \\
\text { Ratio } \\
\end{array}$ & $\begin{array}{l}\text { c. Adanya peningkatan } \\
\text { belanja / pembiayaan } \\
\text { barang dan jasa } \\
\text { (obat-obatan dan } \\
\text { alkes habis pakai) }\end{array}$ \\
\hline 3 & $\begin{array}{l}\text { RASIO } \\
\text { SOLVABILITAS } \\
\text { a. Debt Ratio }\end{array}$ & Turun & $\begin{array}{l}\text { a. Nilai Signifikansi } \\
\text { (alfa) Hitung 0,398> } \\
\text { 0,05. Maka Tidak } \\
\text { Ada Perbedaan } \\
\text { kinerja keuangan } \\
\text { yang yg signifikan } \\
\text { pada aspek Debt } \\
\text { Ratio }\end{array}$ & $\begin{array}{l}\text { a. Biaya opersional rs } \\
\text { sebagaian besar } \\
\text { dibiayai dari utang ( } \\
\text { pembelanjaan tidak } \\
\text { tunai ) }\end{array}$ \\
\hline
\end{tabular}




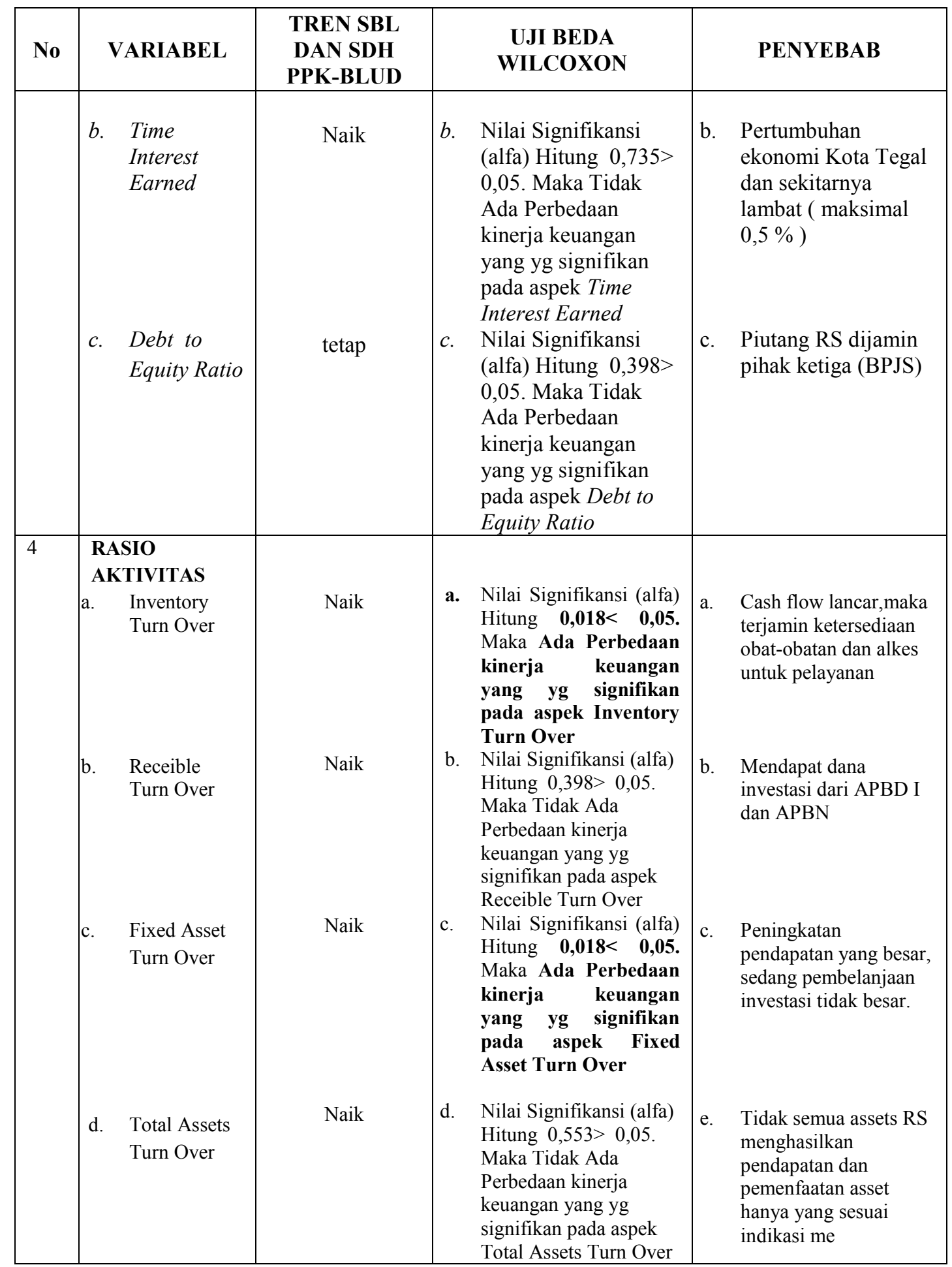

\section{Kesimpulan}

Berdasarkan hasil analis data pembahasan yang diperoleh saat penelitian terhadap Kinerja Keuangan RSUD Kardinah Tegal, sebelum dan setelah ditetapkan sebagai Badan Layanan
Umum Daerah ( BLUD ), maka terdapat beberapa kesimpulan sebagai berikut :

\section{Rentabilitas RSUD Kardinah} sesudah penerapan PPK-BLUD terdapat penurunan dari aspek Gross Profit Margin, Net Profit Margin 
dan Return on Assets. Terdapat peningkatan pada Net Return on Equity. Berdasarkan hasil analisa uji beda Wilcoxon test untuk menguji Rentabilitas keuangan rumah sakit sebelum dan sesudah penerapan PPK-BLUD menunjukkan bahwa Rentabilitas sesudah menerapkan PPK-BLUD tidak menunjukkan perbedaan yang signifikan dibanding dengan sebelum menerapkan PPK-BLUD. Hal ini menunjukkan penerapan PPK-BLUD tidak memberikan peningkatan keuntungan rumah sakit.

2. Likuiditas RSUD Kardinah sesudah penerapan PPK-BLUD terdapat peningkatan dari aspek cash ratio dan quick ratio. Terdapat penurunan pada current ratio dan net working ratio. Berdasarkan hasil analisa uji beda Wilcoxon test untuk menguji Likuiditas keuangan rumah sakit sebelum dan sesudah penerapan PPK-BLUD, menunjukkan bahwa cash ratio, quick ratio dan current ratio sesudah menerapkan PPKBLUD tidak menunjukkan perbedaan yang signifikan dibanding dengan sebelum menerapkan PPKBLUD.

3. Solvabilitas RSUD Kardinah sesudah penerapan PPK-BLUD terdapat peningkatan dari aspek Time Interest Earned, dan penurunan pada aspek Debt Total Asset. Berdasarkan hasil analisa uji beda Wilcoxon test untuk menguji Solvabilitas keuangan rumah sakit sebelum dan sesudah penerapan PPK-BLUD, menunjukkan bahwa sesudah menerapkan PPK-BLUD tidak ada perbedaan yang signifikan dibanding dengan sebelum menerapkan PPK-BLUD.

4. Terdapat peningkatan efisiensi (aktivitas) kinerja keuangan RSUD Kardinah sesudah penerapan PPK-
BLUD pada aspek Inventory Turn Over, Recible Turn Over, Fixed Asset Turn Over dan Total Assets Turn Over. Berdasarkan hasil analisa uji beda Wilcoxon test untuk menguji efisiensi (aktivitas) keuangan rumah sakit sebelum dan sesudah penerapan PPK-BLUD, menunjukkan bahwa Recible Turn Over dan Total Assets Turn Over sesudah menerapkan PPK-BLUD tidak menunjukkan perbedaan yang signifikan dibanding dengan sebelum menerapkan PPK-BLUD. Pada aspek inventory turn over dan fixed asset turn over terdapat perbedaan peningkatan yang signifikan setelah penerapan PPKBLUD.

\section{Saran.}

Secara umum manajemen RSUD Kardinah disarankan untuk dapat mengoptimalkan kinerja keuangan, sebagai BLUDtelah diberikan fleksibilitas pengelolaan keuangan rumah sakit dengan menjalankan prinsip prinsip bisnis yang sehat. Berdasarkan hasil penelitian analisis kinerja keuangan ini disarankan :

1. Untuk meningkatkan rentabilitas keuangan rumah sakit, disarankan pihak Manajemen Rumah Sakit melaksanakan efisiensi biaya operasional rumah sakit dan menghitung unit cost pelayanan sebagai dasar penyusunan tarif baru.

2. Untuk meningkatkan Likuditas keuangan rumah sakit, pihak Manajemen rumah sakit disarankan untuk bernegosiasi dengan BPJS terkait pembayaran klaim dana pelayanan BPJS agar lebih lancar dan tepat waktu, serta meninjau kembali jadwal penagihan piutang agar lebih diperketat, sehingga periode penagihan piutang tidak terlalu lama, untuk 
menjamin cash flow keuangan rumah sakit dapat lancar dan pembayaran utang rumah sakit dapat dibayarkan sebelum jatuh tempo.

3. Untuk meningkatkan Solvabilitas rumah sakit, disarankan pihak manajemen melakukan upaya untuk mendapatkan dana investasi modal dari APBD I dan APBN.
4. Untuk meningkatkan efisiensi (Rasio Aktivitas) rumah sakit, pihak manajemen rumah untuk meningkatkan kelancaran cash flow, dan menjamin ketersediaan obat-obatan dan alkes habis pakai, serta mengoptimalkan pemanfaatan aset rumah sakit terutama alat penunjang medik.

\section{DAFTAR PUSTAKA}

Amalia C., 2015. Analisis Kinerja Keuangan Rumah Sakit Jiwa Prof. HB Sa'anin Sebelum dan Setelah Ditetapkan Sebagai Badan Layanan Umum Daerah (studi Emperis Pada Rumah Sakit Jiwa Prof. HB.Sa'anin), www.academia edu Jurnalanalis, Padang.

Armen F, Azwar V., 2013. Dasar-Dasar Manajemen Keuangan Rumah Sakit, Gosyen Publishing, Yogyakarta.

Darminto DP., 2015. Analisis Laporan Keuangan Konsep dan Aplikasinya, Unit Penerbit dan Percetakan Sekolah Tinggi Ilmu Manajemen YKPN, Yogyakarta.

Faud MR., 2016. Analisis Laporan Keuangan Pemerintah Daerah, Ghalia Indonesia, Bogor.

Halim A., 2015. Manajemen Keuangan Bisnis Konsep dan Aplikasinya, Mitra Wacana Media, Jakarta

Hery., 2015. Analisis Laporan Keuangan Pendekatan Rasio Keuangan, Center for Academic Publishing Service, Yogyakarta.

Ikatan Akuntansi Indonesia., 2012. Standar Akuntansi Keuangan, Salemba Empat, Jakarta.

Kasmir., 2012. Analisis Laporan Keuangan, PT Rajagrafindo Persada, Jakarta.

Masnah., 2014. Analisis Kinerja Keuangan Sebelum dan Sesudah Menjadi Badan Layanan Umum pada RSUP Dr. Mohammad hoesin Palembang, Digital Library Bina Darma.

Majid., Choolis N, Cahyono, Heru, Tohirin., 2009. Evaluasi Antara Kinerja Keuangan dan Operasional pada Satker Rumah Sakit Umum Pemerintah Yang Menerapkan Pola Pengelolaan Badan Layanan Umum, Kajian Akademis, BPPK.

Morissan., 2014. Metode Penelitian Survei, Kencana Prenamedia Group, Jakarta.

Rangkuty F., 2016. SWOT Balanced Scorecard Teknik Menyusun Strategi Korporat yang Efektif plus Cara Mengelola Kinerja Risiko, PT Gramedia Pustaka Utama, Jakarta.

Restiono YE, Bawono IR., 2015. Pengelolaan Keuangan BLU/BLUD, Unit Penerbit dan Percetakan Sekolah Tinggi Ilmu Manajemen YKPN, Yogyakarta. 
Singarimbun M, Effendi S., 1995. Metode Penelitian Survai, LP3ES, Jakarta.

Sugiono A, Untung E., 2016. Panduan Praktis Dasar Analisa Laporan Keuangan, PT Grasindo, Jakarta.

Sugiyono., 2004. Statistik Nonparametris untuk Penelitian, CV Alfabeta, Bandung.

Suharyadi, Purwanto SK., 2004. Statistik untuk Ekonomi dan Keuangan Modern, Salemba Empat, Jakarta.

Suliyanto., 2014. Staistika Nonparametrik dalam Aplikasi Penelitian, CV Andi Offset, Yogyakarta.

Surya SK., 2015. Analisis Kinerja Keuangan dan Non Keuangan Rumah Sakit Umum Daerah Dr. Haryoto Lumajang Sebelum dan Sesudah Implementasi Badan Layanan Umum, Artikel Ilmiah Mahasiswa, Jember.

Suryaningsih R., 2015. Kinerja Keuangan Layanan Kesehatan Sebelum Dan Sesudah Penerapan PPK-BLUD, Jurnal Bisnis \& Manajemen, Vol. 15.

Trisnantoro L., 2004. Memahami penggunaan ilmu ekonomi dalam manajemen rumah sakit, Gajahmada University Press, Yogyakarta.

Wijayanti HT, Sriyanto., 2015. Evaluasi Kinerja Pelayanan dan Keuangan RSUD Yang Menerapkan Pola Pengelolaan Keuangan BLUD Di Subosukowonodraten, Pro-Bank, Journal Ekonomi, Bisnis \& Perbankan, Edisi Maret, Vo1 :1.

Keputusan menteri Kesehatan RI Nomor 550 Tahun 2009 tentang Pedoman Penyusunan Rencana Bisnis dan Anggaran (RBA) BLU RS., 2009. Jakarta.

Peraturan Menteri Dalam Negeri No. 61 Tahun 2007 tentang Pedoman Teknis Pengelolaan Keuangan Badan Layanan Umum Daerah., 2007. Direktorat Jenderal Bina Administrasi Keuangan Daerah, Jakarta.

Peraturan Menteri Keuangan No. 76 Tahun 2008 tentang Sistem Akuntansi dan Pelaporan Keuangan Badan Layanan Umum., 2008, Jakarta.

Peraturan Menteri Kesehatan Republik Indonesia Nomor 4 Tahun 2013 tentang Pedoman Penyusunan Rencana Bisnis dan Anggaran Badan Layanan Umum di lingkungan Ditjen Bina Upaya kesehatan., 2013, Jakarta.

Undang-Undang Kesehatan Republik Indonesia Nomor 36 tahun 2009 tentang Kesehatan, 2009. Jakarta.

Undang-Undang Kesehatan Republik Indonesia Nomor 44 tahun 2009 tentang Rumah Sakit., 2009, Jakarta. 